\title{
Photonics education and training in Ontario, Canada: an integrated plan
}

\section{Marc Nantel, Johann Beda}

Marc Nantel, Johann Beda, "Photonics education and training in Ontario, Canada: an integrated plan," Proc. SPIE 4588, Seventh International Conference on Education and Training in Optics and Photonics, (28 May 2002); doi: $10.1117 / 12.468684$

SPIE Event: Education and Training in Optics and Photonics 2001, 2001, Singapore, Singapore 
Invited Paper

\title{
Photonics education and training in Ontario, Canada : an integrated plan
}

\author{
Marc Nantel, Johann Beda ${ }^{+}$ \\ "Photonics Research Ontario, Suite 331, 60 St-George St., Toronto, ON, Canada M5S 1A7 \\ ${ }^{+}$Physiciens Sans Frontières, 581 Gilmour St., Peterborough, ON, Canada K9H 2K3
}

\begin{abstract}
Canada has established itself as a leader in photonics. Ontario in particular - home of giants such as JDS Uniphase, Nortel Networks, GSI Lumonics and an increasing number of successful start-up companies - has seen the demand for highly-qualified personnel in photonics grow exponentially in the past few years. The scarcity of these photonics experts has become - recent market woes notwithstanding - the single most important impediment to the further growth of photonics companies. Nonetheless, it is mostly at the graduate school level that lasers and photonics are introduced to students, with only very few thus being trained in the field. Photonics Research Ontario has put together an aggressive plan to change this situation and present Optics, Lasers and Photonics at all levels in the education system, from grade school to graduate school. This paper will present this Photonics Education and Training plan, as well as other efforts being undertaken across Canada to address this crucial issue. The paper will focus especially on the training of Photonics Technicians and Technologists in Ontario's Community Colleges. The new curriculum designed for these programmes will be presented, and the importance of industry support will be emphasized.
\end{abstract}

Keywords : Photonics education, photonics training, Ontario, Canada, community college, lasers, optics, optical fibre

\section{INTRODUCTION - A PLAN FOR ONTARIO}

Photonics - the generation, transmission, manipulation, detection, and utilisation of light information and energy - is the world's next multi-trillion dollar industry, according to the United States National Research Council (1). In Ontario, Canada, the photonics industry, including component/module manufacturers and system integrators, has undergone phenomenal growth in the late 1990s: Nortel Networks, JDS Uniphase, Bell Canada Enterprise (all telecommunications-related companies) have accounted for more than $40 \%$ of the Toronto Stock Exchange's TSE 300 index market value. While this sector has recently been hit with severe downsizing, it is more than likely a temporary setback not really indicative of the long-term trends. In any case, more than just a telecommunications technology, photonics is also an enabling technology in a vast array of industries and applications. Specific examples include laser machining and other manufacturing applications, diagnostic and surgical uses in medicine, visualisation and sensing capabilities, imaging, and applications in a variety of other sectors as diverse as tourism and the arts.

\subsection{Photonics experts are in high demand}

Presently, one of the most crucial impediments to the further growth of photonics and photonics-related companies along with recent market woes of telecom-related sector - is the scarcity of highly-qualified personnel with the relevant optics, lasers and photonics training and education. The level of education required is mostly post-secondary, from technicians to Ph.D.s, predominantly in the fields of Physics, Electrical Engineering, and Chemistry.

Currently, Canada has one of the world's most educated populations. According to Statistics Canada (2), Canada leads all other countries in the Organisation for Economic Co-operation and Development (OECD) in the percentage of the population aged 24-65 who completed university or other post-secondary education, based on 1996 data. Canada is also first in the G-7 and second amongst OECD countries in total expenditures on education as a percentage of the Gross National Product (GNP), spending 7\% in 1995, well above the mean of 5.6\% for OECD countries (2,3). Canadian enrollment in Electrical and Computer Engineering (ECE) department are rising more quickly than those in other engineering disciplines, and the demand for admission to ECE programmes is outstripping the universities' ability to accommodate new students (4). Ontario seems particularly successful at increasing its ECE enrollment due to the Access To Opportunity Programme (ATOP), which seeks to double ECE undergraduate rolls. 
Nonetheless, it is predicted that a serious shortage in knowledge workers in Canada is looming. While Ontario's economic growth rate surpassed that of the United States and all other G7 countries in 1991, it had the lowest percentage of graduates from the fields of high-tech and manufacturing engineering among all OECD countries (5). A recent study conducted by $e$ MPOWR Canada predicts a $70 \%$ shortfall in high-tech graduates by 2005 (6). Surveyed high-tech firms project an annual growth rate of 22\%, which translates into over 46,000 new jobs in Canada by 2005 in Microelectronics, Photonics, Opto-electronics, Wireless and Radio (the eMPOWR disciplines). Of these, more than 8,000 will require Masters or Ph.D. qualifications, 23,000 a Bachelor's degree and 15,000 a college diploma. The present rate of output will produce fewer than 10,000 individuals in these disciplines in the same period (6). Some of these numbers are based on calculations pre-dating the present cutbacks in high-tech positions (e.g. 2000-2001 layoffs at Nortel Networks and JDS Uniphase), the layoffs have occurred somewhat outside the photonics highly-qualified personnel area, and the predicted demands should still reflect the medium-to-long-term growth of the industry.

\subsection{Photonics experts are needed at all levels}

In order to address this gaping need in photonics expertise, one needs to attack the problem at all its levels, from grade school to grad school (see figure 1). A comprehensive solution to the demand for photonics experts starts with more grade-school and high-school students being exposed to optics; with more parents and high-school career counselors knowing about photonics and recommending it as a career. What is needed is a clear career path - or indeed several career paths - including Photonics Technician and Technologists diplomas from community colleges, Bachelors of Science and Engineering in Optics from universities, and re-training opportunities for already-employed high-tech workers. While some of these options are offered in a few areas in North America (Rochester, NY, being a good example, with Monroe Community College, the University of Rochester and the Rochester Institute of Technology all offering programmes in photonics/optics), access to a comprehensive suite of programmes in photonics is still rare. Traditionally, students have not been exposed to lasers until having entered graduate school in Physics, Chemistry or Engineering. Not only is this too late in the education pyramid, but this modus operandi only offer Master's and Ph.D.s as photonics experts, failing to address the other levels.

\section{Work Force $\quad$ Credential $\quad$ Educational Institution}

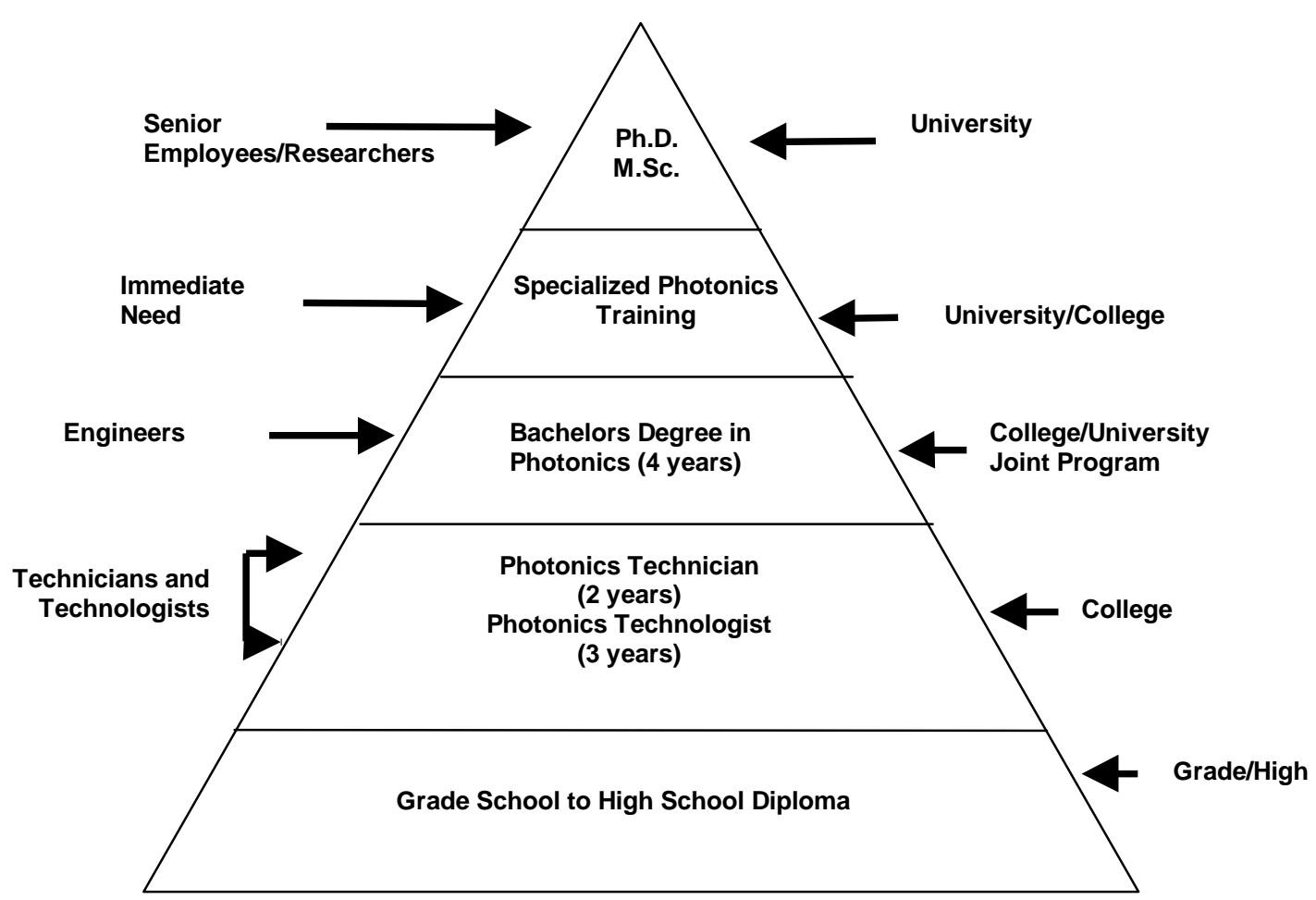

Fig. 1 : Education pyramid, from grade school to grad school. Photonics needs to be taught at all levels, and community awareness fostered. 


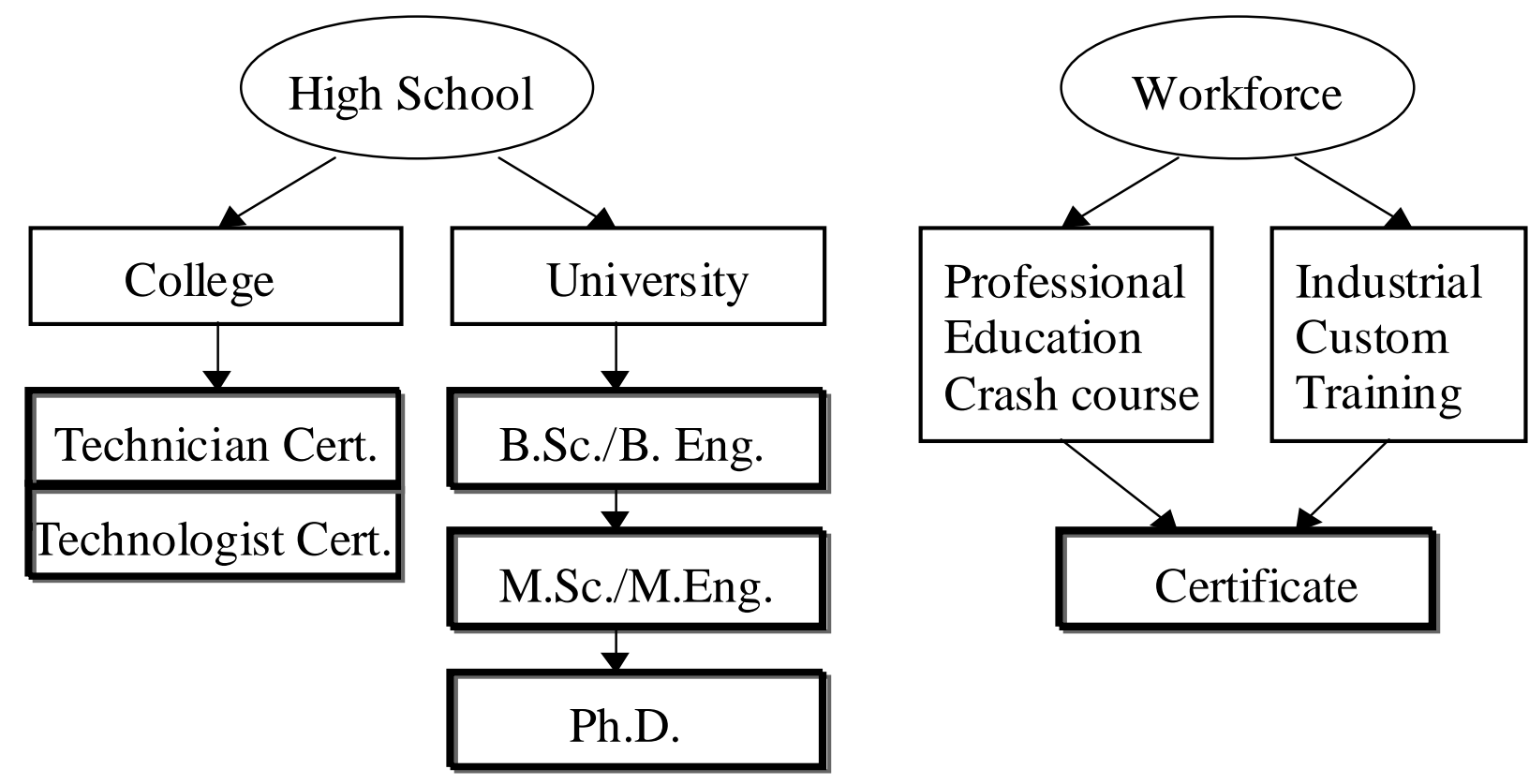

Fig. 2 : Complete education/training coverage. A student coming from high school should have the choice of getting a photonics education through the university or the college paths. A worker wanting to learn about photonics should have the choice of a professional education programme or customized training (provided by Photonics Research Ontario (PRO), community colleges or other training providers). A new graduate or third-year undergraduate university student in a non-photonics degree should be able to take a crash-course in the summer (after graduation or before his/her last year).

There is also a need for technicians, technologists and re-trained employees skilled in photonics. Figure 2 shows the various education paths desirable to have in photonics. A student coming from high school should have the choice of getting a photonics education through the university or the college paths. A worker wanting to learn about photonics should have the choice of a professional education programme or one customized for specific needs. A new graduate or third-year undergraduate university student in a non-photonics degree should be able to take a crash-course in the summer (after graduation or before his/her last year). Of course, recruiting high-school students into science and, eventually, into photonics is imperative.

Photonics Research Ontario (PRO) is tackling all of the above training and education path issues with a variety of partners including the University of Waterloo, the University of Toronto, Vitesse (Re-Skilling) Canada, and others. A new photonics education and training alliance has been formed in June 2001 to address the ever-changing landscape of demand and offer in photonics teaching: the Ontario Photonics Education and Training Association (OPETA). OPETA brings together the various players - clients and suppliers - in photonics education to better coordinate the overall efforts in Ontario. The Association plans to meet four times a year to share information about programmes, opportunities, curriculum advances, with a first annual meeting set to take place during the May 2002 SPIE OPTOCanada conference in Ottawa.

In this paper, we will focus on the Photonics Education and Training (PET) project, aimed at introducing new programmes at Algonquin College and Niagara College to train students to become Technicians and Technologists in Photonics. These programmes have started accepting students in Fall 2001, and the first cohort will graduate in Spring 2004. 


\section{A NEW SUITE OF PROGRAMMES FOR ONTARIO COMMUNITY COLLEGES}

The lack of trained personnel at the technician/technologist level is critical in photonics, and companies typically have to hire graduates in electronics and micro-electronics and retrain them in-house in photonics. Even then, the demand much outstrips the supply: as noted earlier, $e$ MPOWR predicts a need for 15,000 technicians and technologists in hightech fields by 2005 (6), and this is for Canada only. A similar shortfall - scaled-up accordingly - is expected in the United States. Not only are there too few graduates from the programmes available, but corporate in-house training is time-consuming and expensive for the companies.

\subsection{Too few college programmes are currently available}

In Canada, photonics technology diploma programmes are available from a few colleges (average output over the past three years for all combined programmes: 33/year), with a limited number of fast-track or focused programmes. All these programmes are from the province of Québec (7), which has a history of Optics and Lasers education due to a strong presence in the field by Laval University's Centre d'Optique, de Photonique et de Laser (COPL).

In the US, several community colleges and universities offer Associate Degree programmes in photonics, and a search through the SPIE's “Optics Education 2000-2001: Worldwide Directory of Degree Programs in Optics" shows that these represent only about 300-400 potential graduates per year in the entire US (8). The Laser and Electro-Optics Technician (LEOT) programs in the US were started in 1974, and are presently going through a revision. There is also an effort to develop a comprehensive curriculum in photonics for technicians called Scientific and Technological Education in Photonics (STEP), led by faculty at University of Connecticut, and supported by the American National Science Foundation (NSF) and CORD (9). This is a work in progress, and PRO is involved in a consultative role and shares its college curriculum information with STEP.

Elsewhere in the world, Associate Degree Programmes are offered in Armenia, Belgium, France, Russia, and the Ukraine, though it is fair to assume this list is probably incomplete (8).

\subsection{New programmes for Ontario}

PRO is presently leading a new initiative to start programmes at the community college level that will produce Photonics Technicians and Technologists for Ontario companies to hire. This 4-year, \$7.6-million CDN project will enable the establishment of photonics labs at two Ontario community colleges, the development of a completely new suite of courses leading to college diplomas in photonics, and the support for the first cohort of students. The programmes are meant to become part of the colleges' ongoing offerings after the initial 4 years, and to be supported through registration fees and the usual Ontario Ministry of Training, Colleges and Universities (MTCU) grants.

By developing photonics-specific curricula to train technicians and technologists in our Ontario community colleges, we hope to add to the number of available graduates and to the quality and specificity of their training for the photonics industry. The programmes are going to be initially delivered at Niagara College and at Algonquin College, with an output of up to 400 technicians and technologists in the first four years, and with an expected steady-state output of 60 technicians and 50 technologists total per year from 2005 on. The first cohort started classes in September 2001, with students graduating as early as May 2004. The curricula for the programmes have been approved for delivery by the MTCU.

\subsection{Importance of industry support}

This project is supported in part by a \$3.5-million CDN grant from the Ontario Ministry of Economic Development and Trade (MEDT) through their Strategic Skills Investment (SSI) programme. Industrial partners have a strong input into the project, through cash and equipment in-kind donations, as well as through their involvement in curriculum and governance committees. Their total involvement is approximately $\$ 2.5$-million $\mathrm{CDN}$ over the duration of the project. Some of the partners involved with the project are listed in Table 1.

The participation of all three of government, educational institutions and industry is essential for this project. Without the seed fund from the MEDT, up-front costs such as lab renovations, equipment purchase, curriculum development and marketing would be hard to shoulder. Similarly, industry's involvement is critical. Each college will require more than \$1.5-million CDN of equipment, and a good part of that consists of industry donations or discounts on purchases. 


\begin{tabular}{|l|l|}
\hline Optics and lasers, instrumentation : & Imaging and Software : \\
\hline Coherent Laser Group & Apollo Photonics \\
\hline EFOS Canada & Atlantis Systems International \\
\hline GSI Lumonics & Christie Digital Systems \\
\hline Melles Griot Canada & Dipix Technologies \\
\hline Newport Instruments Canada & Photonix Imaging \\
\hline Optikon & SORIC \\
\hline Passat Lasers & \\
\hline Spectra Research Corporation & Industry associations : \\
\hline & Ontario Photonics Technology Industry Cluster (OPTIC) \\
\hline Telecommunications : & Ottawa Photonics Cluster (OPC) \\
\hline Exfo Electro-Optical Engineering & \\
\hline JDS Uniphase & Universities : \\
\hline Nortel Networks & Carleton University \\
\hline Sirific & University of Toronto \\
\hline & \\
\hline Manufacturing : & Government : \\
\hline Eurocopter Canada & National Research Council of Canada \\
\hline General Motors of Canada & Niagara Economic and Tourism Corporation \\
\hline John Deere & \\
\hline
\end{tabular}

Table 1 : List of partners associated with the PET project with PRO, Niagara College and Algonquin College.

This allows us to train the students on the very best equipment, with the techniques that they will be using once they enter the workforce. Another crucial role that the industrial partners are playing is to guide the project through its starting stages. Industry partners are prominently featured with members in both the project's Photonics Industry Advisory Group (PIAG) and Joint Photonics Project Team (JPPT). It is the PIAG's mandate to guide the development of the curriculum, including the subjects to be taught, the equipment to buy, and the textbooks to use. The PIAG provided the curriculum developer with a critical window into the needs of the various industry sectors requiring highly-qualified photonics personnel. The JPPT is the project's equivalent of a Board of Directors, and its mandate is to look at general governance issues, including the milestones and deliverables of the projects, and relationships between the project and the governmental, industrial and educational partners. The continuing relationship with present industry partners and the recruitment of new ones is crucial to the long-term survival of the programmes, since our courses and labs have to be kept up-to-date and well equipped. This will not be possible without the regular donation from industry of time, equipment and funds.

\section{THE CURRICULA FOR PHOTONICS TECHNICIANS AND TECHNOLOGISTS}

While the PET project encompasses short certificates, preparatory programmes, and specialized training on a contract basis, the foundation of the programme is the two-year technician diploma and the three-year technology diploma. Working with the MTCU, we have created province-wide college programme standards for both diplomas.

We have put together a series of programme components designed to deliver well-defined, broad-learning outcomes for the graduates rather than proscribing very specific technologies that could change as the field advances. For the programmes' implementation and delivery, there will be institution-specific curricula with specific courses containing the programme components and learning outcomes from the generic curricula. This allows for delivery and organizational differences between institutions while still providing a clear common structure. The parts of the generic curricula could be presented in various combinations appropriate for the delivery method chosen by each institution.

The four-semester Photonics Engineering Technician Programme will prepare graduates to install, test, maintain, and repair, as well as troubleshoot, a variety of photonics equipment and systems. The six-semester Photonics Engineering Technology Programme will prepare graduates to design, analyze, troubleshoot, as well as commission, install, and repair, a variety of photonics equipment, and systems. In general, the Technician tests and maintains while the Technologist designs and analyzes. In addition, graduates will be able to participate in quality control and assurance 
programmes and to apply communication, documentation, computer applications, information technology, and teamwork skills to support the engineering activities of an organization.

Offering two categories of diplomas (Technicians and Technologists) involves more choices for the students and the employers, as opposed to the American model where only the 2-year LEOT program is available. In addition to the 2year and 3-year programmes, the community college structure in Ontario allows for the future implementation of a 1year "Techniques" programme. This Techniques programme would be intended for students coming directly from high school and is meant to train for trades. While there will be a need for photonics assemblers when the telecom sector rebounds - as there was before the current difficulties - our project does not intend to establish such 1-year training programmes until it is clear that the demand is there. Our project will offer short diploma programmes for students having already earnt a college diploma or a university degree in engineering or the sciences wishing to gain experience in photonics fields.

Graduates of these programmes will work in a broad range of employment settings in companies using photonics engineering, in both large and small organizations. Their employment could involve working in various photonics environments including those relating to optical systems manufacturing, telecommunications, manufacturing, bio/medical applications, and imaging.

The following outlines consist of the generic curricula for the various Photonics programmes, broken down into generic "programme components" (a "component" is roughly speaking equivalent to a 3-5 hour-per-week college course), for each semester of the programme. Note that components with a plain number (no "Tn" or "Ty") are common to both the Technician (Tn) and the Technologist (Ty) diplomas. The current outline only has common English, Safety and Computer components. This does not mean that much $\mathrm{Tn} / \mathrm{Ty}$ material and modules will not be shared, but such details are left to the particular colleges to implement as is appropriate. The colleges and the province require various general education courses, with a variety of student choices possible. Each programme will have one 3-hour course per semester that is a "general education" course, which usually means it is non- programme derived.

Arguably the most important part of any programme of study is the fundamentals of the field. As with any technical field, photonics includes mathematics and physics. Without a solid foundation in those two subjects, more advanced material is of little use. Balanced against this is the need to keep the students' interest with applications of these foundation skills to the field of study and the desire to expose the students to a wide variety of different areas of photonics within the short time available.

Graduates of our programmes are unlikely to end up working only with photonics equipment and photonics specialists. They will need the ability to communicate with specialists in other fields and to know the broad abilities and limitations of those fields without necessarily being experts themselves. Our programmes must therefore give the students the opportunity for a comprehensive introduction to these fields. The programmes follow the work in mathematics and physics with offerings in electricity/electronics, computing, mechanics and manufacturing methods in addition to the necessary exposure to the areas of photonics needed for a well-rounded photonics technician or technologist : optics, lasers, imaging, communications, and manufacturing.

\subsection{Photonics Engineering Technician Diploma}

The four-semester Photonics Engineering Technician diploma consists of the components listed in Table 2. For the Technician programme, while the first year of instruction is weighted towards the non-photonics "foundation" subjects, we have attempted to provide the students with extensive photonics-based examples and practical applications within those subjects. Additionally, we have created a "General Education" course with wide appeal, called "Trends in Photonics Technologies". This course should provide students a wide exposure to a variety of sub-fields of photonics.

In the Technician's second year of study, the programme focuses more time and resources on the photonics-specific subject material. Students are given extensive opportunity to build hands-on experience with a variety of devices and techniques as they learn skills needed for various employment settings in companies using photonics engineering. We and our industrial partners want our graduates to be able to quickly learn new employer-specific skills and so our programmes focus is on broad fundamentals rather than on perfecting very limited application skills or techniques. 


\begin{tabular}{|l|l|l|}
\hline First Year & & \\
\hline $\begin{array}{l}\text { Number of } \\
\text { Hours/week }\end{array}$ & Component Title & Description \\
\hline $3-4$ & Comp 1 & Programming \\
\hline $5-6$ & Elect Tn1 & Electronic Fundamentals Tn \\
\hline 3 & English 1 & Applied Communication \\
\hline 4 & Math Tn1 & Algebra I Tn \\
\hline 4 & Math Tn2 & Algebra II Tn \\
\hline 3 GE & Photo 1 & Trends in Photonics Tech \\
\hline $5-6$ & Photo Tn2 & Optics/Optical Fibre Principles Tn \\
\hline $5-6$ & Physics Tn1 & Optics and Wave Tn \\
\hline $5-6$ & Physics Tn2 & Kinematics/Dynamics Tn \\
\hline 3 GE & Safety 1 & Occupational Health \& Safety \\
\hline Second Year & & \\
\hline $\begin{array}{l}\text { Number of } \\
\text { Hours/week }\end{array}$ & Component Title & Description \\
\hline $3-4$ & Comp 2 & \\
\hline $4-5$ & Elect Tn2 & Interfacing \\
\hline $4-5$ & Elect Tn3 & Semiconductors and Logic Tn \\
\hline $3-4$ & Math Tn3 & Telecommunications Tn \\
\hline $4-5$ & Photo Tn3 & Statistics Tn \\
\hline $4-5$ & Photo Tn4 & Fundamentals of Light Sources Tn \\
\hline $4-5$ & Photo Tn5 & Optic/Optical Fibre Devices Tn \\
\hline $4-5$ & Photo Tn6 & Laser Systems Tn \\
\hline $4-5$ & Photo Tn7 & Manufacturing Photonics Components \\
\hline 3 GE & Elective & Photonics Manufacturing Systems Tn \\
\hline 3 GE & Elective & General Education Elective \\
\hline
\end{tabular}

Table 2 : Photonics Technician. Hours indicated are estimates of the time per week for completion of various components. Lab time, in particular, may be increased to provide more hands-on experience for students.

\subsection{Photonics Engineering Technology Diploma}

The six-semester Photonics Engineering Technology diploma consists of the components listed in Table 3. As with the Technician programme, the Technology programme's first year of instruction is weighted towards the non-photonics "foundation" subjects, with introductory computing and electronics as well as the Gen-Ed course Trends in Photonics Technologies.

In the second year of study, the Technology programme focuses more time and resources on the photonics specific subject material and lays the groundwork for the more advanced material covered in the final year. As with the Technician programme graduates, the focus is on exposing the students to a wide variety of material with an emphasis on building a solid foundation for further specialization. The third year of the Technology programme gives the student (and the institution) an opportunity to explore more specialized subject matters through advanced courses and individualized research projects.

\subsection{Other uses for the curriculum}

The main cost - in dollars and in time - of setting up these programmes are the curriculum research and development, industry consultation, lab renovations and equipment purchases. Once the programmes are established and the curricula have been piloted through the first cohort of students, the curricula will be available for "cloning" to be delivered at other community colleges, in Canada and abroad. The incremental cost to a college for setting up the equivalent programmes will be less than $\$ 2.5$-million CDN (mostly equipment), some of which can be raised through in-kind donations from industry partners, others they might already have through their other technology programmes (oscilloscopes, computers, basic physics equipment). Several other Ontario colleges have already shown interest in starting their own Photonics Programmes based on ours, but with their particular twist on the content based on their 


\begin{tabular}{|c|c|c|}
\hline First Year & & \\
\hline $\begin{array}{l}\text { Number of } \\
\text { Hours/week }\end{array}$ & Component Title & Description \\
\hline $3-4$ & Comp 1 & Programming \\
\hline 5 & Elect Ty1 & Electronic Fundamentals Ty \\
\hline 3 & English 1 & Applied communications \\
\hline 4 & Math Ty1 & Algebra Ty \\
\hline 4 & Math Ty2 & Intro. to Calculus Ty \\
\hline $3 \mathrm{GE}$ & Photo 1 & Trends in Photonics Tech \\
\hline $5-6$ & Photo Ty02 & Optics/Optical Fibre Principles Ty \\
\hline $5-6$ & Physics Ty1 & Optics and Wave Ty \\
\hline $5-6$ & Physics Ty2 & Kinematics/Dynamics Ty \\
\hline $3 \mathrm{Ge}$ & Safety 1 & Occupational Healthy \& Safety \\
\hline \multicolumn{3}{|l|}{ Second Year } \\
\hline $\begin{array}{l}\text { Number of } \\
\text { Hours/week }\end{array}$ & Component Title & Description \\
\hline $3-4$ & Comp 2 & Interfacing \\
\hline $4-5$ & Elect Ty2 & Semiconductors and Logic Ty \\
\hline $4-5$ & Elect Ty3 & Telecommunications Ty \\
\hline $3-4$ & Math Ty3 & Statistics Ty \\
\hline $3-4$ & Math Ty4 & Integration and Apps Ty \\
\hline $3-4$ & Math Ty5 & Diff Eqn Ty \\
\hline $4-5$ & Photo Ty03 & Fundamentals of Light Sources Ty \\
\hline $4-5$ & Photo Ty04 & Optic/Optical Fibre Devices Ty \\
\hline $4-5$ & Photo Ty05 & Laser Systems Ty \\
\hline $4-5$ & Photo Ty06 & Manufacturing Photonics Components Ty \\
\hline $3 \mathrm{GE}$ & Elective & General Education Elective \\
\hline $3 \mathrm{GE}$ & Elective & General Education Elective \\
\hline \multicolumn{3}{|l|}{ Third Year } \\
\hline $\begin{array}{l}\text { Number of } \\
\text { Hours/week }\end{array}$ & Component Title & Description \\
\hline 3 & English 2 & Technical Communications \\
\hline $4-5$ & Man Ty1 & Control Systems \\
\hline $4-5$ & Photo Ty07 & Photonics Manufacturing Systems Ty \\
\hline $4-5$ & Photo Ty08 & Advanced Optical Systems Ty \\
\hline $4-5$ & Photo Ty09 & Opto-Electronic Devices Ty \\
\hline $4-5$ & Photo Ty10 & Imaging, Image/Signal Processing Ty \\
\hline $4-5$ & Photo Ty11 & Laser-Matter Interactions Ty \\
\hline $3-4$ & Photo Ty12 & Photonics Research Project Ty \\
\hline $3-4$ & Physics Ty3 & Fluid and Vacuum Systems Ty \\
\hline $3-4$ & Physics Ty4 & Heat Transfer Ty \\
\hline $3 \mathrm{GE}$ & Elective & General Education Elective \\
\hline $3 \mathrm{GE}$ & Elective & General Education Elective \\
\hline
\end{tabular}

Table 3 : Photonics Technologist. Hours indicated are estimates of the time per week for completion of various components. Lab time, in particular, may be increased to provide more hands-on experience for students.

local industry needs (for example: automotive/manufacturing applications, biomedical photonics applications or packaging applications). There is also some interest from several quarters to offer our curricula on-line. Private universities in Ontario and in Australia have already contacted us on the matter. The challenge in this case is to deliver the content without laboratories, which form in our case a critical part of the training. 
Finally, the enabling capacities of this project have made it possible for Niagara and Algonquin colleges to offer 8month or shorter certificate programmes in photonics for students who already have diplomas or degrees in a technology or science field. This will make photonics personnel available to industry more quickly, and will allow graduates from different disciplines to turn onto photonics and increase their employability in that field. It is expected that 40 graduates per year will complete such certificate programmes once steady-state output has been reached. The colleges also offer customized industry training using the equipment put in place through this project, in an effort to further speed-up the training of photonics personnel for industry. Students have already completed programs at Algonquin College, where several classes (including some from the welfare system) have learnt about lasers, optical fibre splicing and optics assembly. Finally, the colleges are forming partnerships with universities and private companies for access to their labs on a contract basis. Algonquin College and Carleton University are already working together on a joint undergraduate degree programme in information technology.

\section{CONCLUSION}

The photonics industry in Canada - and more particularly in Ontario - will need highly-qualified people to grow and prosper. At the present, too few are trained or being trained in photonics, with most graduating with an M.Sc. or a Ph.D. degree. An integrated solution to the staffing of photonics companies needs to be implemented from grade school to graduate school, and make continuing education training available in photonics.

In particular, Photonics Research Ontario is leading the Photonics Education and Training project, which is implementing its Photonics Technician and Technologist programmes at Niagara and Algonquin community colleges. Labs have been renovated, equipment has been and is being purchased, and the first cohort of students started in September 2001. The delivery of the curricula is still being established as the courses come on-line, and the project is presently in the piloting stage. Great attention will be paid to the students' progress, their input into the courses and their placement rates once graduated. The curricula developed through this project will become the standard for photonics training at community colleges in Ontario and, if the demand justifies it, across all Canada.

\section{ACKNOWLEDGMENTS}

This project is supported by Photonics Research Ontario, Algonquin College, Niagara College, industry partners and a grant from the Ontario Ministry of Economic Development and Trade. The authors thank the management teams at each colleges, in particular Bonnie Rose, Marti Jurmain, Bob Birrell, Leo Tiberi, Jack Treuhaft, Ray Proulx, and Peter Casey, as well as members of the PIAG and JPPT committees. At PRO, Gerry Lynch, Reuben Sokol, Helen Chen, Sharon Telem, Eleanor Harper and Olga Velarde deserve our thanks for helping make this project possible.

\section{REFERENCES}

1. Harnessing Light: Optical Science and Engineering for the $21^{\text {st }}$ Century, National Research Council, National Academy Press, Washington, DC (1998).

2. John Zhao, Doug Drew, and T. Scott Murray, Brain Drain and Brain Gain: The Migration of Knowledge Workers from and to Canada, Education Quarterly Review, 6, 8 (2000) (Statistics Canada - Catalogue no. 81003); Scott Murray, Brain Drain, Brain Gain: Sessions Proceedings (Caledon Institute of Social Policy, May 2000).

3. Human Resource Development Canada and Industry Canada presentation, International Migration of Skilled Workers: Facts and Factors (December 1999); also referring to OECD, Education at a Glance (1998).

4. Jeremy Leonard, François Nicolas Pelletier, Survey of Student and Faculty Trends in Canadian University Electrical and Computer Engineering Programs, preliminary (not for quotation) report for a study conducted by the Canadian Institute for Telecommunications Research (CITR, November 2000).

5. Building Ontario's Future, A SuperBuild Progress Report, Ontario SuperBuild (December 2000).

6. $\quad$ The National Information Technology Initiative document (NITI, 31 August 2000).

7. TECHNOCompétences, Urgence Main-d'Oeuvre pour l'Optique-Photonique au Québec (9 January 2001).

8. Optics Education 2000-2001: Worldwide Directory of Degree Programs in Optics, Society of Photo-Optical Instrumentation Engineers (SPIE, 2000).

9. Scientific and Technological Education in Photonics, The University of Connecticut, The National Science Foundation and CORD. 